Article

\title{
Dihydrogen Phosphate Stabilized Ruthenium((0) Nanoparticles: Efficient Nanocatalyst for The Hydrolysis of Ammonia-Borane at Room Temperature
}

\section{Feyyaz Durap ${ }^{1}$, Salim Caliskan ${ }^{2}$, Saim Özkar ${ }^{2}$, Kadir Karakas ${ }^{3}$ and Mehmet Zahmakiran ${ }^{3, *}$}

1 Department of Chemistry, Dicle University, Diyarbakir 21280, Turkey;

E-Mail: fdurap@dicle.edu.tr

2 Department of Chemistry, Middle East Technical University, Ankara 06800, Turkey;

E-Mails: sirshalim@yahoo.com (S.C.); sozkar@metu.edu.tr (S.O.)

3 NanoMatCat Research Laboratory, Department of Chemistry, Yüzüncü Y1l University, Van 65080, Turkey; E-Mail: kadirkarakash@gmail.com

* Author to whom correspondence should be addressed; E-Mail: zmehmet@yyu.edu.tr; Tel.: +90-432-225-18-00 (ext. 2243); Fax: +90-432-225-18-06.

Academic Editor: Umit Demirci

Received: 29 May 2015 / Accepted: 7 July 2015 / Published: 10 July 2015

\begin{abstract}
Intensive efforts have been devoted to the development of new materials for safe and efficient hydrogen storage. Among them, ammonia-borane appears to be a promising candidate due to its high gravimetric hydrogen storage capacity. Ammonia-borane can release hydrogen on hydrolysis in aqueous solution under mild conditions in the presence of a suitable catalyst. Herein, we report the synthesis of ruthenium( 0 ) nanoparticles stabilized by dihydrogenphosphate anions with an average particle size of $2.9 \pm 0.9 \mathrm{~nm}$ acting as a water-dispersible nanocatalyst in the hydrolysis of ammonia-borane. They provide an initial turnover frequency (TOF) value of $80 \mathrm{~min}^{-1}$ in hydrogen generation from the hydrolysis of ammonia-borane at room temperature. Moreover, the high stability of these ruthenium( 0 ) nanoparticles makes them long-lived and reusable nanocatalysts for the hydrolysis of ammonia-borane. They provide 56,800 total turnovers and retain $\sim 80 \%$ of their initial activity even at the fifth catalytic run in the hydrolysis of ammonia-borane at room temperature.
\end{abstract}

Keywords: hydrogenphosphate; ammonia-borane; hydrolysis; catalyst; ruthenium nanoparticles 


\section{Introduction}

Hydrogen is globally considered to be an efficient and clean energy carrier because of its abundance and high energy density [1,2]. However, as the low density of hydrogen makes it difficult to store in compressed or liquefied form [3,4], safe storage and effective release of hydrogen from the storage materials are required for practical fuel cell applications of hydrogen-based technologies [5-7]. Recent studies have already shown that ammonia-borane $\left(\mathrm{NH}_{3} \mathrm{BH}_{3} ; \mathrm{AB}\right)$ is one of the most promising candidates for chemical hydrogen storage [8,9] because of its low molecular weight $\left(30.9 \mathrm{~g} \cdot \mathrm{mol}^{-1}\right)$, high hydrogen content $\left(19.6 \% \mathrm{wt}, 6.5 \% \mathrm{wt}\right.$ for the first equivalents of $\mathrm{H}_{2}$ and $13.1 \%$ wt for the second equivalents of $\mathrm{H}_{2}$ ) which is greater than the 2015 target of U.S. Department of Energy (5.5\% wt $\mathrm{H}_{2}$ ) [10,11], nontoxicity, and high stability under ambient conditions for potential fuel cell applications. The catalytic hydrolysis reaction is the preferred way to release hydrogen from AB [12-14] because $\mathrm{AB}$ has high solubility in water $(33.6 \mathrm{~g} / 100 \mathrm{~g}$ water) $[15,16]$ and has high stability in aqueous solution against self-hydrolysis [17]. The controllable release of three equivalent $\mathrm{H}_{2}$ per mole of $\mathrm{AB}$ can be achieved at appreciable rate from the hydrolysis of $\mathrm{AB}$ (Equation (1)) in the presence of a suitable catalyst at room temperature $[18,19]$ :

$$
\mathrm{NH}_{3} \mathrm{BH}_{3}+2 \mathrm{H}_{2} \mathrm{O} \rightarrow \mathrm{NH}_{4} \mathrm{BO}_{2}+3 \mathrm{H}_{2}
$$

To date, various homogeneous [20,21] and heterogeneous [11,22,23] catalysts have been tested in the hydrolysis of $\mathrm{AB}$. Of particular importance, the examples of heterogeneous catalysts that provide notable catalytic performances are ruthenium(0) nanoparticles (NPs) supported on carbon nanotube [5], platinum NPs supported on carbon [24], colloidal rhodium(0) NPs [25], Ni1-xPt hollow nanospheres [26], ruthenium(0), rhodium(0) and platinum(0) NPs supported on $\gamma-\mathrm{Al}_{2} \mathrm{O}_{3}$ [27], palladium(0) NPs supported on carbon [28] or grapheme [29], iron(0) NPs [30], $\mathrm{Co}(0) / \mathrm{Co} 2 \mathrm{~B}$ and $\mathrm{Ni}(0) / \mathrm{Ni} 3 \mathrm{~B}$ [31], poly(N-vinyl-2-pyrrolidone) stabilized nickel(0) NPs [32], transition metal-based alloy catalysts [33], hollow $\mathrm{Ni}-\mathrm{SiO}_{2}$ nanosphere [34], water soluble laurate stabilized ruthenium(0) [35] and rhodium(0) NPs [36], poly(4-styrenesulfonic acid-co-maleic acid) stabilized ruthenium(0) and palladium(0) NPs [3], zeolite confined copper(0) NPs [23], nickel(0) [37], cobalt(0) [38], palladium(0) [39] and rhodium(0) NPs [40].

The aforementioned studies clearly reveal that the majority of heterogeneous catalysts that show high performance in the hydrolysis of $\mathrm{AB}$ are transition metal NP-based catalytic systems. It is well-known that the use of transition metal NPs enhances catalytic activity as the fraction of surface atoms increases with the decreasing particle size [41]. However, these highly reactive transition metal(0) NPs need to be stabilized against agglomeration, which causes a significant decrease in catalytic activity. We have recently reported the synthesis of water-soluble ruthenium(0) NPs stabilized by hydrogenphosphate ion and their catalytic activity in hydrogen generation from the hydrolysis of dimethylamine-borane $\left(\left(\mathrm{CH}_{3}\right)_{2} \mathrm{NHBH}_{3}\right)$ at $25 \pm 0.1{ }^{\circ} \mathrm{C}$ [42]. The hydrogen phosphate anion has been suggested as a stabilizer for transition metal NPs with atomic size matching to the O-O distance in phosphate ion $[43,44]$. The high catalytic performance observed for these novel water soluble ruthenium(0) NPs in the hydrolysis of dimethylamine-borane $\left(\left(\mathrm{CH}_{3}\right)_{2} \mathrm{NHBH}_{3} ; \mathrm{DMAB}\right)$ prompted us to test the same nanocatalyst in the hydrolysis of AB. Herein, we report the catalytic performance of 
water-soluble dihydrogen phosphate stabilized ruthenium(0) NPs in terms of activity, lifetime and reusability in the hydrolysis of $\mathrm{AB}$ under mild conditions.

\section{Experimental Section}

\subsection{Materials}

Ruthenium(III) chloride trihydrate $\left(\mathrm{RuCl}_{3} .3 \mathrm{H}_{2} \mathrm{O}\right)$, tetrabutylammonium phosphate monobasic $\left(\left(\mathrm{CH}_{3} \mathrm{CH}_{2} \mathrm{CH}_{2} \mathrm{CH}_{2}\right)_{4} \mathrm{~N}\left[\mathrm{OP}(\mathrm{OH})_{2} \mathrm{O}\right]\right.$, 99\%), dimethylamine borane $\left(\left(\mathrm{CH}_{3}\right)_{2} \mathrm{NHBH}_{3}, 97 \%\right)$, and ammonia-borane $(\mathrm{AB})\left(\mathrm{H}_{3} \mathrm{NBH}_{3}, 99 \%\right)$ were purchased from Aldrich. Ethanol $\left(\mathrm{C}_{2} \mathrm{H}_{5} \mathrm{OH}\right)$ was purchased from Merck. The water content of $\mathrm{RuCl}_{3} \cdot x \mathrm{H}_{2} \mathrm{O}$ was determined by TGA and found to be $x=3$. Deionized water was distilled by water purification system (Milli Q-pure WS). All glassware and Teflon coated magnetic stir bars were cleaned with acetone, followed by copious rinsing with distilled water before drying in an oven at $150{ }^{\circ} \mathrm{C}$.

\subsection{Preparation of Water Soluble Dihydrogen Phosphate Stabilized Ruthenium(0) Nanoparticles}

The synthesis of dihydrogen phosphate anion stabilized ruthenium(0) NPs was carried out by a slight modification of our previously reported method [42]. In a $20.0 \mathrm{~mL}$ Schlenk tube ruthenium(III) chloride $\left(\mathrm{RuCl}_{3} .3 \mathrm{H}_{2} \mathrm{O}, 0.02 \mathrm{mmol}\right)$ was dissolved in $10.0 \mathrm{~mL}$ deionized water. Then $0.40 \mathrm{mmol}$ tetrabutylammoniumdihydrogen phosphate was added to this solution. After stirring the solution for half an hour at room temperature 0.10 mmol DMAB was added to the reaction mixture. The solution gradually changed its colour from dark red to brown during the reaction at room temperature. The colour change was completed within two hours. The change in colour from dark red to brown is indicative of the formation of ruthenium(0) NPs. The colloidal dihydrogenphosphate anion stabilized ruthenium(0) NPs were found to be stable in aqueous medium, no precipitation was observed after two days of storage under ambient conditions.

\subsection{Transmission Electron Microscopy Analyses}

The dihydrogenphosphate anion-stabilized ruthenium( $(0)$ NPs isolated from the reaction solution by centrifugation were re-dispersed in dichloromethane and one drop of this colloidal solution was deposited on the chloroform-cleaned, carbon-coated $\mathrm{Cu}$ TEM grid and the solvent was then evaporated under inert gas atmosphere. Transmission electron microscopy (TEM) images were taken by using a Philips CM-12TEM with a $70 \mu \mathrm{m}$ lens operating at $100 \mathrm{kV}$ and with a $2.0 \AA$ point-to-point resolution. Samples were examined at magnification between 100 and $400 \mathrm{~K}$.

\subsection{Testing the Catalytic Activity of Ruthenium(0) Nanoparticles in the Hydrolysis of Ammonia-Borane}

The catalytic activity of ruthenium(0) NPs in the hydrolysis of AB was determined by measuring the rate of hydrogen generation. To determine the rate of hydrogen generation the catalytic reactions were performed in a Fischer-Porter pressure bottle modified with Swagelock TFE-sealed quick connects and connected to an Omega PX-302 pressure transducer interfaced through an Omega D1131 digital transmitter to a computer using the RS-232 module. The progress of an individual hydrolysis 
reaction was followed by monitoring the increase of $\mathrm{H}_{2}$ pressure on Lab View 8.0 program. The pressure $v s$. time data was processed using Microsoft Office Excel 2003 and Origin 7.0 then converted into the proper unit [volume of hydrogen $(\mathrm{mL})$ ] by using the stoichiometry given in Equation 1. In a typical experiment, $30.9 \mathrm{mg}(1.0 \mathrm{mmol}) \mathrm{AB}$ was dissolved in $10.0 \mathrm{~mL}$ water, (corresponding to a maximum amount of $3.0 \mathrm{mmol}=67.0 \mathrm{~mL} \mathrm{H}_{2}$ at $25.0 \pm 0.1^{\circ} \mathrm{C}$ ). This solution was transferred with a $50.0 \mathrm{~mL}$ glass-pipette into the FP bottle thermostated at $25.0 \pm 0.1{ }^{\circ} \mathrm{C}$. Then, aliquot of dihydrogen phosphate anion stabilized ruthenium(0) NPs from the $2.0 \mathrm{mM}$ stock solution was transferred into the FP bottle. The experiment was started by closing the FP bottle connected to the pressure transducer and turning on stirring at $1000 \mathrm{rpm}$ simultaneously. When no more hydrogen generation was observed, the experiment was stopped; an aliquot was then transferred into a quartz NMR sample tube, which was subsequently sealed and then brought out for ${ }^{11} \mathrm{~B}$ NMR analysis. NMR spectra were recorded on a Bruker Avance DPX $400 \mathrm{MHz}$ spectrometer (128.2 MHz for $\left.{ }^{11} \mathrm{~B} \mathrm{NMR}\right)$. The conversion of $\mathrm{AB}$ to ammonium metaborate $\left(\mathrm{NH}_{4} \mathrm{BO}_{2}\right)$ was further checked by comparing the ${ }^{11} \mathrm{~B}$ NMR signal intensities of $\mathrm{AB}$ and metaborate anion at $\delta=-23.9$ and $9 \mathrm{ppm}$, respectively, in the spectra of the solution.

\subsection{Determination of Activation Energy for Ruthenium(0) Nanoparticles Catalyzed Hydrolysis of} Ammonia-Borane

In a typical experiment, ruthenium(0) NPs $(0.50 \mathrm{mM} \mathrm{Ru})$ catalyzed hydrolysis of $\mathrm{AB}(100 \mathrm{mM})$ was performed by following the same procedure as described in the previous section at various temperatures $\left(10,15,20,25,30,35^{\circ} \mathrm{C}\right)$ to obtain the apparent activation energy $\left(\mathrm{E}_{\mathrm{a}}\right)$.

\subsection{Determination of Catalytic Lifetime of Ruthenium(0) Nanoparticles in the Hydrolysis of} Ammonia-Borane

The catalytic lifetime of ruthenium(0) NPs in the hydrolysis of AB was determined by measuring the total turnover number (TTO). The lifetime experiment was started with a $10.0 \mathrm{~mL}$ aqueous solution containing ruthenium $(0) \mathrm{NPs}(0.10 \mathrm{mM})$ and $\mathrm{AB}(200 \mathrm{mM})$ at $25.0 \pm 0.1{ }^{\circ} \mathrm{C}$. When the complete conversion of $\mathrm{AB}$ had been achieved, more ammonia-borane was added until no hydrogen gas evolution was observed.

\subsection{Recyclability of Ruthenium(0) Nanoparticles in the Hydrolysis of Ammonia-Borane}

The recyclability of ruthenium(0) NPs in the hydrolysis of AB was determined by a series of experiments started with a $10.0 \mathrm{~mL}$ solution containing ruthenium $(0) \mathrm{NPs}(0.50 \mathrm{mM})$ and $\mathrm{AB}(100 \mathrm{mM})$ at $25.0 \pm 0.1{ }^{\circ} \mathrm{C}$. When the complete conversion is achieved, immediately, another batch of fresh $\mathrm{AB}$ $(100 \mathrm{mM})$ was added, leading to further hydrogen evolution from the reaction mixture. 


\section{Results and Discussion}

\subsection{Catalytic Activity of Water-Soluble Dihydrogen Phosphate-Stabilized Ruthenium(0) Nanoparticles in the Hydrolysis of Ammonia-Borane}

The water soluble dihydrogen phosphate stabilized ruthenium(0) NPs were prepared from the reduction of the aqueous mixture of ruthenium(III) chloride and tetrabutylammoniumdihydrogen phosphate by DMAB at room temperature, which were then isolated and characterized as described elsewhere [42]. The resulting ruthenium(0) NPs were tested as a heterogeneous catalyst in the hydrolysis of $\mathrm{AB}$ (Figure 1). Figure 1a shows the plots of volume of $\mathrm{H}_{2}$ generated versus time during the catalytic hydrolysis of $\mathrm{AB}$ solution in the presence of ruthenium(0) NPs at different ruthenium concentrations $(0.25,0.50,1.00,2.00 \mathrm{mM})$ and $25.0 \pm 0.1{ }^{\circ} \mathrm{C}$. Linear hydrogen generation starts immediately without an induction period, as the experiment was started with a preformed ruthenium catalyst, and continues until the complete consumption of $\mathrm{AB}$ present in the reaction medium. ${ }^{11} \mathrm{~B}-\mathrm{NMR}$ spectrum of the reaction solution taken at the end of hydrolysis of $\mathrm{AB}$ shows that the triplet signal of $\mathrm{AB}$ at $\delta=-23.9 \mathrm{ppm}$ is completely converted to the singlet of the metaborate anion at $\delta=9 \mathrm{ppm}[19,24]$. The catalytic activity of Ru NPs in the hydrolysis of AB shows variation with the ruthenium concentration as seen from the inspection of plots shown in Figure 1a. Expectedly, the rate of hydrogen generation increases with the increase of ruthenium(0) concentration; with $2.0 \mathrm{mM} \mathrm{Ru}$ concentration the reaction is completed within 3.5 minutes at $25.0 \pm 0.1{ }^{\circ} \mathrm{C}$. It is noteworthy that the resulting ruthenium(0) NPs are acting as active catalysts even at low ruthenium( 0 ) concentrations; for example, at $0.25 \mathrm{mM} \mathrm{Ru}$ concentration (substrate/catalyst ratio $=400$ ) the catalytic reaction is completed within 15 minutes by yielding $3.0 \mathrm{~mol} \mathrm{H} / \mathrm{mol} \mathrm{AB}$ at $25.0 \pm 0.1{ }^{\circ} \mathrm{C}$. The quantity of ammonia liberated during ruthenium(0) NP-catalyzed hydrolysis of AB was investigated via control tests using copper(II) sulfate or an acid/base indicator, which showed no ammonia evolution in detectable amount in the experiments [45]. The rate of hydrogen generation was determined from the linear portions of each plot given in Figure 1a and used to calculate the turnover frequency (TOF) values for the hydrolysis of $\mathrm{AB}$ at different catalyst concentrations and $25.0 \pm 0.1{ }^{\circ} \mathrm{C}$. Figure $1 \mathrm{~b}$ indicates that the TOF values decrease with the increase of catalyst concentration, which is most likely due to the growing particle size. As we kept dihydrogen phosphate concentration at a constant value and increased the ruthenium concentration, under these circumstances one can expect an increase in the size of ruthenium(0) nanoparticles [46].

The catalytic activity was determined in terms of turnover frequency ( $\mathrm{TOF}=\mathrm{mol} \mathrm{H} / \mathrm{mol}$ catalyst $\times$ time) and it was found to be $80 \mathrm{~mol} \mathrm{H} / \mathrm{mol} \mathrm{Ru}$.min when the ruthenium concentration is 0.25 or $0.50 \mathrm{mM}$ (Figure $1 \mathrm{~b}$ ), which is higher than that obtained by using $\mathrm{Ru}_{0} \mathrm{Al}_{2} \mathrm{O}_{3}$ catalyst ( $39.6 \mathrm{~mol} \mathrm{H} / \mathrm{mol} \mathrm{Ru}$.min) [47] and laurate stabilized $\mathrm{Ru}(0) \mathrm{NPs}(75 \mathrm{~mol} \mathrm{H} / \mathrm{mol} \mathrm{Ru}$.min) [35] but lower than that obtained by using Ru/C (430 mol H2/mol Ru.min) [48], Ru@MWCNT (329 mol H2/mol Ru.min) [5] and PSSA-Co-MA stabilized $\mathrm{Ru}(0) \mathrm{NPs}$ (172 mol H$/ 2 / \mathrm{mol} \mathrm{Ru} . \mathrm{min})$ [3]. The hydrogen generation rate increases with the ruthenium concentration (observed rate constants ( $\left.\mathrm{k}_{\mathrm{obs}}\right)$ : 0.0704, 0.1409, 0.2254 and $0.322 \mathrm{~mL} \cdot \mathrm{min}^{-1}$ for $[\mathrm{Ru}]: 0.25,0.50,1.00$ and $2.00 \mathrm{mM}$ respectively). When the hydrogen generation rate is plotted against ruthenium concentration (on logarithmic scale), one obtains a straight line with a slope of 0.84 (Figure 1c), which is indicative of the ruthenium(0) NP-catalyzed hydrolysis of AB 
proceeds first order with respect to the catalyst concentration. The effect of ammonia-borane concentration on the hydrogen generation rate was also investigated. Figure 2 summarizes the results of a series of experiments performed for ruthenium(0) NP-catalyzed hydrolysis of $\mathrm{AB}$ starting with various $\mathrm{AB}$ concentrations $(50,100,200,400 \mathrm{mM})$ at $25.0 \pm 0.1{ }^{\circ} \mathrm{C}$. The logarithmic plot of observed initial rates versus $A B$ concentration gives a straight line with a slope of 0.50 . Thus, it indicates that the rate of ruthenium(0) NP-catalyzed hydrolysis of $\mathrm{AB}$ depends on the substrate concentration, at least in the range studied here.
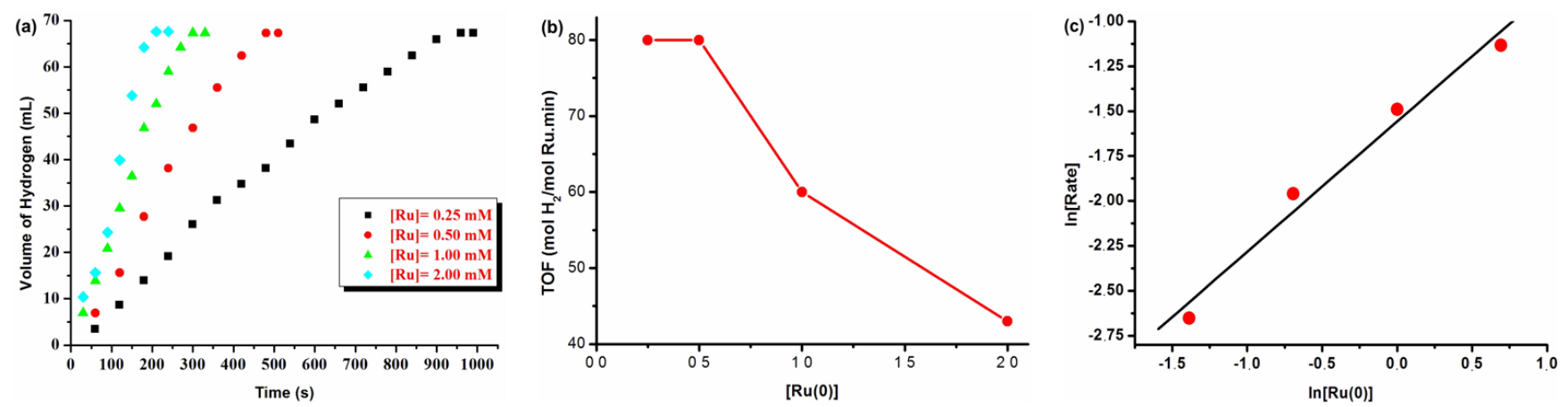

Figure 1. (a) The volume of hydrogen versus time graph for the ruthenium(0) NP-catalyzed hydrolysis of $\mathrm{AB}(100 \mathrm{mM})$ started with different ruthenium concentrations at $25.0 \pm 0.1{ }^{\circ} \mathrm{C}$; (b) plot of initial TOF values versus catalyst concentration; (c) plot of hydrogen generation rate versus the catalyst concentration, both in logarithmic scale.

(a)

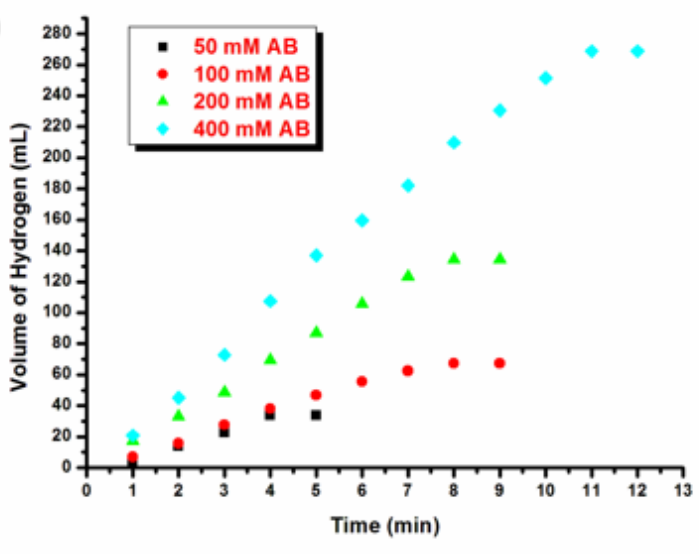

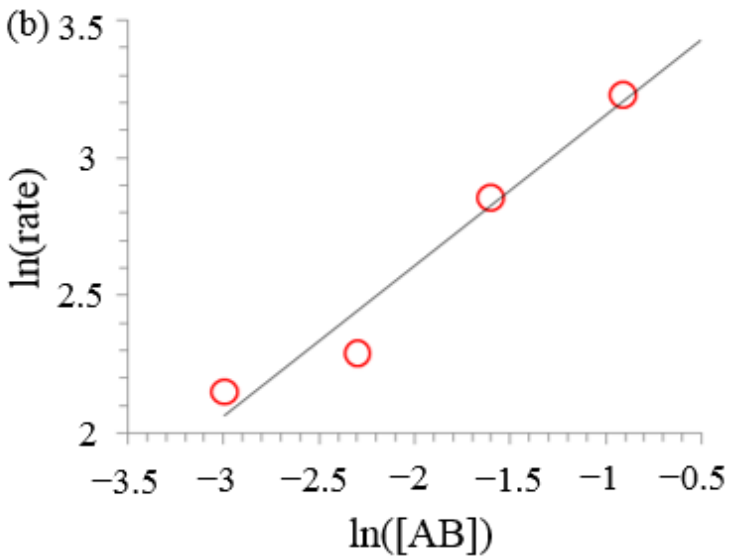

Figure 2. (a) The plots of volume of hydrogen generated versus time for the ruthenium(0) $\mathrm{NP}(0.50 \mathrm{mM})$ catalyzed hydrolysis of $\mathrm{AB}$ starting with different $\mathrm{AB}$ concentrations in the range of $50-400 \mathrm{mM}$ at $25.0 \pm 0.1{ }^{\circ} \mathrm{C}$; (b) the logarithmic plot of hydrogen generation rate versus ammonia-borane concentration, both in logarithmic scale, for the same reaction.

Furthermore, ruthenium(0) NPs show significant catalytic activity in the hydrolysis of AB even at low temperatures (Figure 3). For example, they achieve the generation of 3.0 equivalents $\mathrm{H}_{2}$ per mole of $\mathrm{AB}$ with an initial TOF value of $31.6 \mathrm{~min}^{-1}$ at $10.0 \pm 0.1{ }^{\circ} \mathrm{C}$. This is the highest TOF value reported for the catalytic hydrolysis of $\mathrm{AB}$ at such a low temperature. Figure 3 shows the plots of hydrogen volume versus time for ruthenium(0) NP-catalyzed hydrolysis of AB at various temperatures. As expected, the rate of hydrogen generation increases with temperature. 


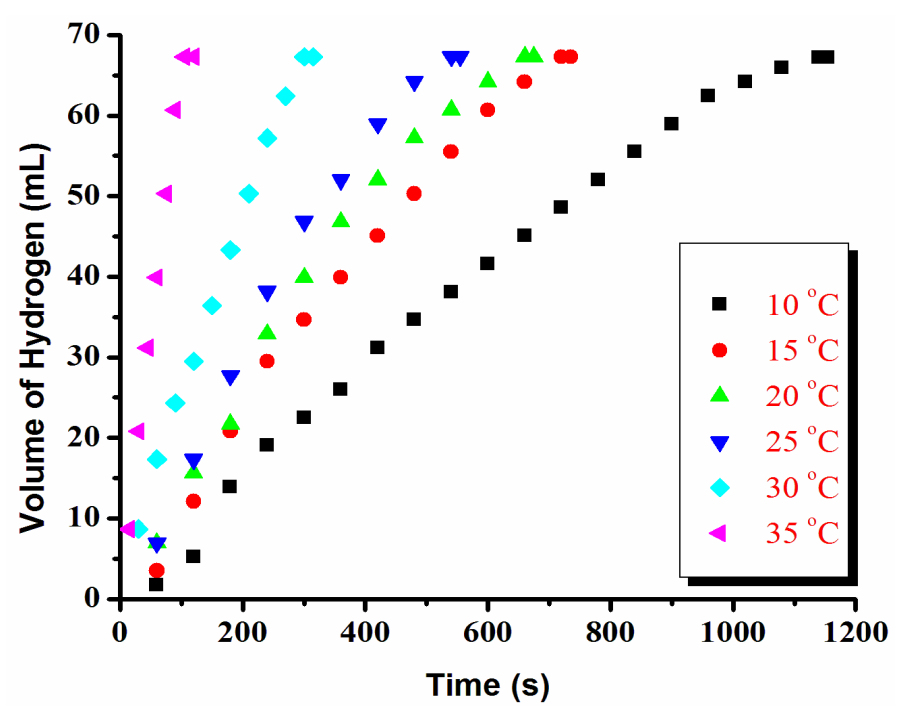

Figure 3. Volume of hydrogen versus time graph for the dihydrogen phosphate anion stabilized ruthenium(0) NP-catalyzed hydrolysis of $\mathrm{AB}$ at different temperatures $([\mathrm{Ru}]=0.50 \mathrm{mM},[\mathrm{AB}]=100 \mathrm{mM})$.

The values of the observed rate constant (kobs) were measured from the linear portion of each plot given in Figure 3 at six different temperatures and used for the construction of an Arrhenius plot (Figure 4). The activation energy for ruthenium(0) NP-catalyzed hydrolysis of $\mathrm{AB}$ was found to be $E_{\mathrm{a}}=69 \pm 2 \mathrm{~kJ} \cdot \mathrm{mol}^{-1}$ from the Arrhenius plot. This value is higher than those reported in the literature for the same reaction by using $\mathrm{Rh} / \gamma-\mathrm{Al}_{2} \mathrm{O}_{3}\left(21 \mathrm{~kJ} \cdot \mathrm{mol}^{-1}\right), \mathrm{Ru} / \gamma-\mathrm{Al}_{2} \mathrm{O}_{3} \quad\left(23 \mathrm{~kJ} \cdot \mathrm{mol}^{-1}\right)$ [27], $\mathrm{Ru}(0) @ \mathrm{MWCNT}\left(33 \mathrm{~kJ} \cdot \mathrm{mol}^{-1}\right)$ [5], laurate-stablized rhodium $(0)\left(43 \mathrm{~kJ} \cdot \mathrm{mol}^{-1}\right)$ [36] and ruthenium(0) NPs $\left(47 \mathrm{~kJ} \cdot \mathrm{mol}^{-1}\right)$ [35], but nevertheless smaller than the values reported in the literature for the same reaction obtained by using nickel powder $\left(70 \mathrm{~kJ} \cdot \mathrm{mol}^{-1}\right)$ [26] and ruthenium/C $\left(76 \mathrm{~kJ} \cdot \mathrm{mol}^{-1}\right)$ [49].

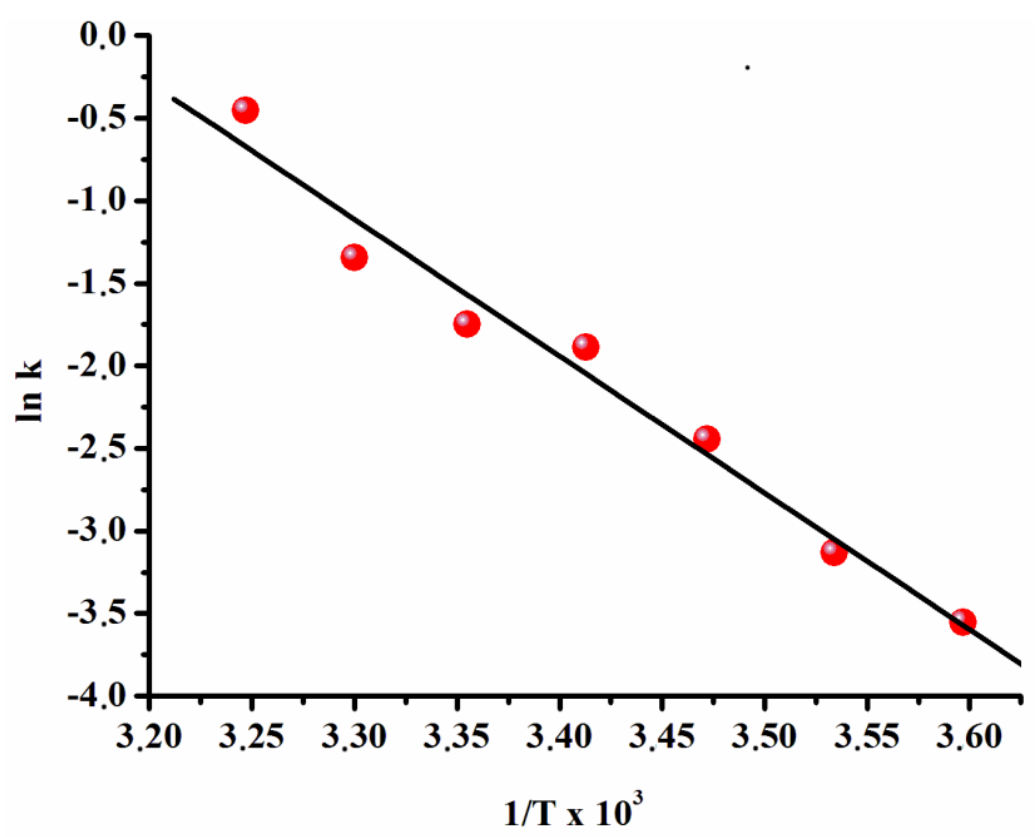

Figure 4. Arrhenius plot for the dihydrogen phosphate anion-stabilized ruthenium $(0)$ NP-catalyzed hydrolysis of $\mathrm{AB}([\mathrm{Ru}]=0.50 \mathrm{mM},[\mathrm{AB}]=100 \mathrm{mM})$. 


\subsection{Recyclability and Catalytic Lifetime of Ruthenium(0) Nanoparticles in the Hydrolysis of} Ammonia-Borane

The recyclability and catalytic lifetime of ruthenium(0) NPs in the hydrolysis of AB were also explored by performing a series of experiments. When the complete conversion is achieved in the first run for ruthenium(0) NP-catalyzed hydrolysis of $\mathrm{AB}$, another batch of a fresh equal amount of $\mathrm{AB}$ was immediately added to the reaction, and this protocol was continued up to fifth catalytic run. The results of these experiments reveal that water soluble dihydrogen phosphate stabilized ruthenium(0) NPs retain $78 \%$ of their inherent activity and achieve complete conversion at the fifth catalytic run. The slight decrease in the activity throughout the successive runs may be attributed to the passivation of nanoparticles surface due to the increasing concentration of the metaborate anion, which reduces the accessibility of active sites on the surface of nanoparticles catalyst [25]. Additionally, TEM image given in Figure 5 for the ruthenium(0) NPs sample harvested after the fifth catalytic run shows the aggregation of ruthenium(0) nanoparticles, which can also lead to a reduction in catalytic activity. The corresponding size histogram of ruthenium( $(0)$ NPs harvested after the fifth catalytic run reveals that the size of the ruthenium(0) NPs increased to $47.3 \pm 5.5 \mathrm{~nm}$ at the end of the hydrolysis of ammonia-borane. It should be noted that the mean size of fresh ruthenium(0) NPs prepared using the same methodology was found to be $2.9 \pm 0.9 \mathrm{~nm}$ [42].

(a)

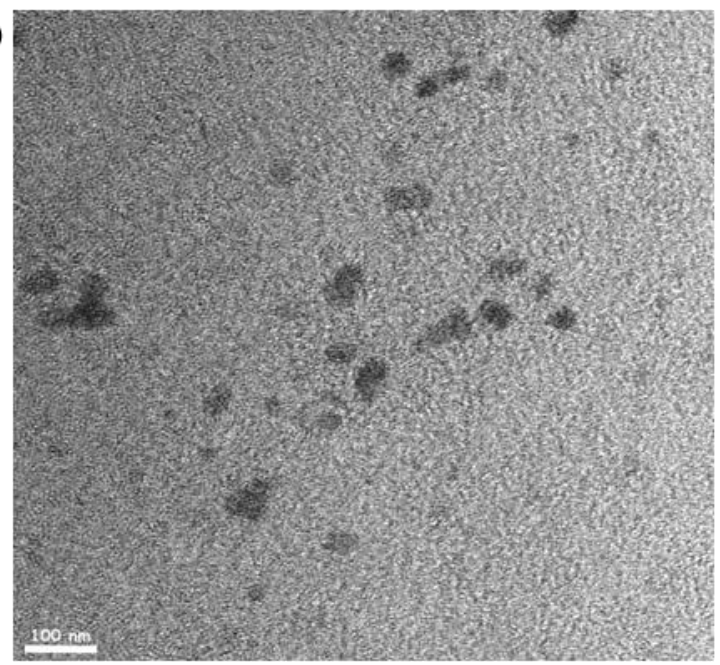

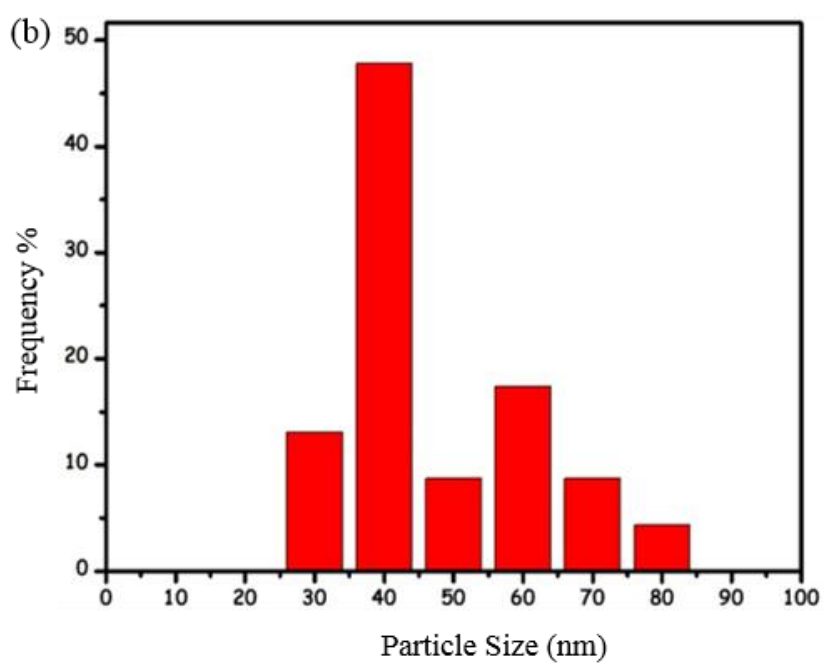

Figure 5. (a) TEM image of a dihydrogen phosphate anion stabilized ruthenium( $(0) \mathrm{NP}$ sample harvested after the fifth run of hydrolysis of $\mathrm{AB}$ (the scale bar corresponds to $100 \mathrm{~nm}$ ); and (b) corresponding size histogram.

The catalytic lifetime of ruthenium(0) NPs was determined by measuring the total turnover number (TTO) in the hydrolysis of ammonia-borane. Before the complete consumption of $\mathrm{AB}$ present in reaction solution, a new batch of $\mathrm{AB}$ was added to provide continuity in the hydrogen generation. The addition of $\mathrm{AB}$ is repeated until no more hydrogen evolution was observed. Figure 6 depicts the plot of turnover number versus time determined throughout the catalytic lifetime experiment. Ruthenium $(0)$ NPs, when stabilized, provide 56,800 turnovers over $34 \mathrm{~h}$ before deactivation in the hydrolysis of $\mathrm{AB}$ at $25.0 \pm 0.1{ }^{\circ} \mathrm{C}$ (Figure 6). This catalytic lifetime value recorded by dihydrogen phosphate-stabilized ruthenium(0) NPs is higher than that of obtained by using PSSA-Co-MA-stabilized ruthenium(0) NPs 
(51720 mol H2/mol Ru) [3], RhNPs@zeolite (47200 mol H2/mol Rh) [40], Ru@MWCNT (26400 $\mathrm{mol} \mathrm{H} / \mathrm{mol} \mathrm{Ru}$ ) [5] but lower than that produced using laurate-stabilized rhodium(0) NPs

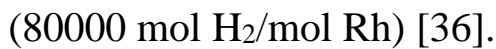

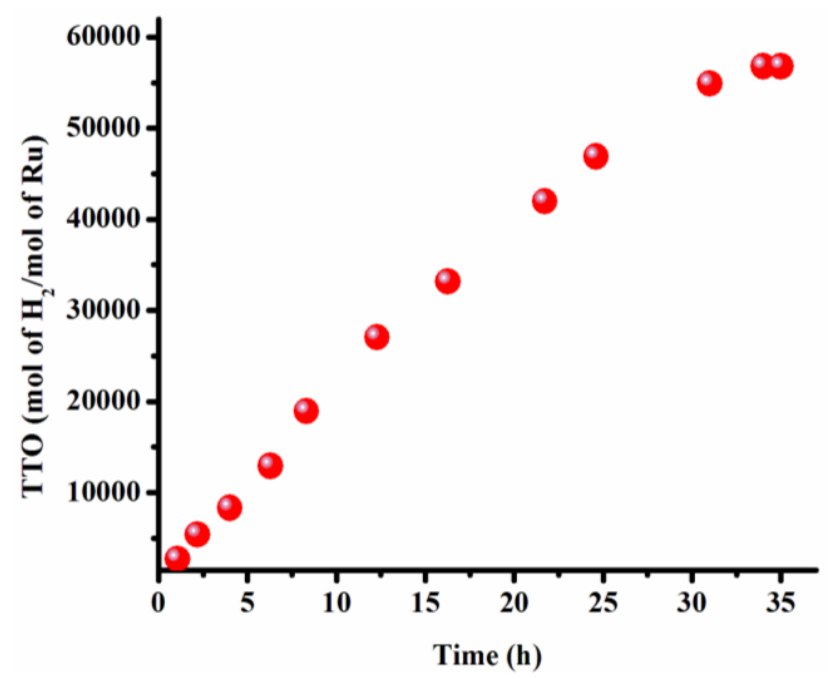

Figure 6. Total turnover number (TTO) versus time for the catalytic lifetime of ruthenium(0) NPs $(0.50 \mathrm{mM})$ in the hydrolysis of ammonia-borane at $25.0 \pm 0.1^{\circ} \mathrm{C}$.

\section{Conclusions}

In summary, water-soluble ruthenium(0) NPs stabilized dihydrogen phosphate anion were readily prepared and employed as catalyst in the catalytic hydrolysis of $\mathrm{AB}$ under mild conditions. The resulting ruthenium( 0 ) NPs show significantly high catalytic activity in the hydrolysis of ammonia-borane even at low catalyst concentration and temperature. More importantly, they were found to be long-lived heterogeneous catalysts, providing 56,800 turnovers over $34 \mathrm{~h}$ in the hydrolysis of $\mathrm{AB}$ at $25.0 \pm 0.1{ }^{\circ} \mathrm{C}$. The stability of these ruthenium( $(0)$ NPs was also investigated, and their recycling tests show that they retain $78 \%$ of their initial activity at complete conversion in the hydrolysis of $\mathrm{AB}$, so they can be reused successively in this reaction. In summary, our study reveals that the easy preparation and high catalytic performance of water-soluble ruthenium( 0 ) nanoparticles stabilized by dihydrogen phosphate make them a promising heterogeneous catalyst system for efficient hydrogen generation from the hydrolysis of $\mathrm{AB}$.

\section{Acknowledgments}

The partial support from the Scientific and Technological Research Council of Turkey (TUBITAK-2218-Research Fellowship for FD), Fevzi Akkaya Scientific Activities Support Fund (FABED), and Science Academy and Turkish Academy of Sciences (TUBA) is gratefully acknowledged.

\section{Author Contributions}

Feyyaz Durap and Salim Caliskan performed the experiments, Mehmet Zahmakiran and Saim Özkar designed the experiments, discussed results and wrote the paper, and Kadir Karakas performed the control experiments and did the studies required in the revision of the manuscript. 


\section{Conflicts of Interest}

The authors declare no conflict of interest.

\section{References}

1. Sperling, D.; DeLuchi, M.A. Transportation energy futures. Annu. Rev. Energy 1989, 14, 375-424.

2. Schlapbach, L.; Züttel, A. Hydrogen-storage materials for mobile applications. Nature 2001, 414, 353-358.

3. Yu, W.; Porosoff, M.D.; Chen, J.G. Review of Pt-based bimetallic catalysis: From model surfaces to supported catalysts. Chem. Rev. 2012, 112, 5780-5817.

4. Metin, Ö.; Şahin, Ş.; Özkar, S. Water-soluble poly(4-styrene sulfonic acid-co-maleic acid) stabilized ruthenium(0) and palladium(0) nanoclusters as highly active catalyst in hydrogen generation from the hydrolysis of ammonia-borane. Int. J. Hyd. Energy 2009, 34, 6304-6313.

5. Wu, B.H.; Zheng, N.F. Surface and interface control of noble metal nano crystals for catalytic and electrocatalytic applications. Nano Today 2013, 8, 168-197.

6. Guo, S.J.; Wang, E.K. Noble metal nanomaterials: Controllable synthesis and application in fuel cells and analytical sensors. Nano Today 2011, 6, 240-264.

7. Akbayrak, S.; Özkar, S. Ruthenium(0) nanoparticles supported on multiwalled carbon nanotube as highly active catalyst for hydrogen generation from ammonia borane. ACS Appl. Mater. Interfaces 2012, 4, 6302-6310.

8. Basic Research Needs Catalysis for Energy, Report from the US Department of Energy, Basic Energy Sciences Workshop Report. Available online: http://www.sc.doe.gov/bes/reports/list.html (accessed on 6 August 2007).

9. Marder, T. Will we soon be fueling our automobiles with ammonia-borane? Angew. Chem. Int. Ed. 2007, 46, 8116-8118.

10. Satyapala, S.; Petrovic, J.; Read, C.; Thomas, G.; Ordaz, G. The U.S. department of energy's national hydrogen storage project: Progress towards meeting hydrogen-powered vehicle requirements. Catal. Today 2007, 120, 246-256.

11. Zahmakıran, M. Preparation and characterization LTA-type zeolite framework dispersed ruthenium nanoparticles and their catalytic application in the hydrolytic dehydrogenation of ammonia-borane for efficient hydrogen generation. Mater. Sci. Eng. B 2012, 177, 606-613.

12. Wolf, G.; Baumann, J.; Baitalow, F.; Hoffmann, F.P. Calorimetric process monitoring of thermal decomposition of B-N-H compounds. Thermochim. Acta 2000, 343, 19-25.

13. Gutowska, A.; Li, L.; Shin, Y.; Wang, C.M.; Li, X.S.; Linehan, J.C.; Smith, R.S.; Kay, B.D.; Schmid, B.; Shaw, W.; et al. Nanoscaffold mediates hydrogen release and the reactivity of ammonia borane. Angew. Chem. Int. Ed. 2005, 44, 3578-3582.

14. Bluhm, M.E.; Bradley, M.G.; Butterick, R.; Kusari, U.; Sneddon, L.G. Amineborane-based chemical hydrogen storage: Enhanced ammonia borane dehydrogenation in ionic liquids. J. Am. Chem. Soc. 2006, 128, 7748-7749.

15. Stephens, F.H.; Pons, V.; Baker, R.T. Ammonia-borane: The hydrogen source par excellence? Dalton Transactions 2007, 25, 2613-2626. 
16. Proceedings of the 2002 U.S. DOE Hydrogen Program Review. Available online: http://www.eere.energy.gov/hydrogenandfuelcells/pdfs/32405b15.pdf (accessed on 17 April 2015).

17. Chandra, M.; Xu, Q. Dissociation and hydrolysis of ammoniaborane with solid acids and carbon dioxide: An efficient hydrogen generation system. J. Power Sources 2006, 159, 855-860.

18. $\mathrm{Xu}, \mathrm{Q}$; Chandra, M. Catalytic activities of non-noble metals for hydrogen generation from aqueous ammonia-borane at room temperature. J. Power Sources 2006, 163, 364-370.

19. $\mathrm{Xu}, \mathrm{Q}$.; Chandra, M. A portable hydrogen generation system: Catalytic hydrolysis of ammonia-borane. J. Alloys Compd. 2007, 446, 729-732.

20. Graham, T.W.; Tsang, C.W.; Chen, X.; Guo, R.; Jia, W.; Lu, S.M.; Sui-Sen, C.; Ewart, C.B.; Lough, A.; Amoroso, D.; et al. Catalytic solvolysis of ammonia borane. Angew. Chem. Int. Ed. 2010, 49, 8708-8711.

21. Fortman, G.C.; Slawin, A.M.Z.; Nolan, S.P. Highly active iridium(III)-NHC system for the catalytic B-N bond activation and subsequent solvolysis of ammonia-borane. Organometallics 2011, 30, 5487-5492.

22. Staubitz, A.; Robertson, A.; Manners, I. Ammonia-borane and related compounds as dihydrogen sources. Chem. Rev. 2010, 110, 4079-4124.

23. Zahmakıran, M.; Durap, F.; Özkar, S. Zeolite confined copper(0) nanoclusters as cost-effective and reusable catalyst in hydrogen generation from the hydrolysis of ammonia-borane. Int. J. Hydrogen Energy 2010, 35, 187-197.

24. Chandra, M.; Xu, Q. A high performance hydrogen generation system: Transition metal-catalyzed dissociation and hydrolysis of ammonia-borane. J. Power Sources 2006, 156, 190-194.

25. Clark, T.J.; Whittell, G.R.; Manners, I. Highly efficient colloidal cobalt- and rhodium-catalyzed hydrolysis of $\mathrm{H}_{3} \mathrm{~N}-\mathrm{BH}_{3}$ in air. Inorg. Chem. 2007, 46, 7522-7527.

26. Cheng, F.; Ma, H.; Li, Y.; Chen, J. Ni-x $\mathrm{Pt}_{\mathrm{x}}(\mathrm{x}=0-0.12)$ hollow spheres as catalysts for hydrogen generation from ammonia borane. Inorg. Chem. 2007, 46, 788-794.

27. Chandra, M.; Xu, Q. Room temperature hydrogen generation from aqueous ammonia-borane using noble metal nanoclusters as highly active catalysts. J. Power Sources 2007, 168, 135-142.

28. Ramachandran, P.V.; Gagare, P.D. Preparation of ammonia borane in high yield and purity, methanolysis, and regeneration. Inorg. Chem. 2007, 46, 7810-7817.

29. Metin, Ö.; Kayhan, E.; Özkar, S.; Schneider, J.J. Palladium nanoparticles supported on chemically derived graphene: An efficient and reusable catalyst for the dehydrogenation of ammonia borane. Int. J. Hydrogen Energy 2012, 37, 8161-8169.

30. Yan, J.M.; Zang, X.B.; Han, S.; Shioyama, H.; Xu, Q. Iron nanoparticle catalyzed hydrolytic dehydrogenation of ammonia-borane for chemical hydrogen storage. Angew. Chem. Int. Ed. 2008, 47, 2287-2289.

31. Kalindindi, S.B.; Indirani, M.; Jagirdar, B.R. First row transition metal ion-assisted ammonia-borane hydrolysis for hydrogen generation. Inorg. Chem. 2008, 47, 7424-7429.

32. Umegaki, T.; Yan, J.M.; Zhang, X.B.; Shioyama, H.; Kuriyama, N.; Xu, Q. Preparation and catalysis of poly(N-vinyl-2-pyrrolidone) (PVP) stabilized nickel catalyst for hydrolytic dehydrogeneration of ammonia borane. Int. J. Hydrogen Energy 2009, 34, 3816-3822.

33. Yao, C.F.; Zhuang, L.; Cao, Y.L.; Ai, X.P.; Yang, H.X. Hydrogen release from hydrolysis of borazane on Pt- and Ni-based alloy catalysts. Int. J. Hydrogen Energy 2008, 33, 2462-2467. 
34. Umegaki, T.; Yan, J.M.; Zhang, X.B.; Shioyama, H.; Kuriyama, N.; Xu, Q. Hollow Ni-SiO2 nanosphere-catalyzed hydrolytic dehydrogenation of ammonia borane for chemical hydrogen storage. J. Power Sources 2009, 191, 209-216.

35. Durap, F.; Zahmakıran, M.; Özkar, S. Water soluble laurate stabilized ruthenium(0) nanoclusters catalyst for hydrogen generation from the hydrolysis of ammonia-borane: High activity and long life time. Int. J. Hydrogen Energy 2009, 34, 7223-7230.

36. Durap, F.; Zahmakıran, M.; Özkar, S. Water soluble laurate stabilized rhodium(0) nanoclusters catalyst: Unprecedented catalytic lifetime in the hydrolytic dehydrogenation of ammonia-borane. Appl. Catal. A. General 2009, 369, 53-59.

37. Zahmakıran, M.; Ayvalı, T.; Akbayrak, S.; Çalışkan, S.; Çelik, D.; Özkar, S. Zeolite framework stabilized nickel(0) nanoparticles: Active and long-lived catalyst for hydrogen generation from the hydrolysis of ammonia-borane and sodiumborohydride. Catalysis Today 2011, 170, 76-84.

38. Rakap, M.; Özkar, S. Hydrogen generation from the hydrolysis of ammonia-borane using intrazeolite cobalt(0) nanoclusters catalyst. Int. J. Hydrogen Energy 2010, 35, 3341-3346.

39. Rakap, M.; Özkar, S. Zeolite confined palladium(0) nanoclusters as effective and reusable catalyst for hydrogen generation from the hydrolysis of ammonia-borane. Int. J. Hydrogen Energy 2010, $35,1305-1312$.

40. Zahmakıran, M.; Özkar, S. Zeolite framework stabilized rhodium(0) nanoclusters catalyst for the hydrolysis of ammonia-borane in air: Outstanding catalytic activity, reusability and life time. Appl. Catal. B 2009, 89, 104-110.

41. Pool, R. Clusters: Strange morsels of matter: when metals or semiconductor are shrunk down to clumps only 10 or 100 atoms in size, they become a "totally new class of materials" with potentially valuable applications. Science 1990, 248, 1186-1188.

42. Çalışkan, S.; Zahmakıran, M.; Durap, F.; Özkar, S. Hydrogen liberation from the hydrolytic dehydrogenation of dimethylamine-borane at room temperature by using a novel ruthenium nanocatalyst. Dalton Trans. 2012, 41, 4976-4984.

43. Özkar, S.; Finke, R.G. Transition-metal nanocluster stabilization fundamental studies: Hydrogenphosphate as a simple, effective, readily available, robust and previously unappreciated stabilizer for well-formed, isolable, and redissolvable $\operatorname{Ir}(0)$ and other transition-metal nanoclusters. Langmuir 2003, 19, 6247-6260.

44. Özkar, S.; Finke, R.G. Molecular insights for how preferred oxoanions bind to and stabilize transition-metal nanoclusters: A tridentate, C3 symmetry, lattice size-matching binding model. Coord. Chem. Rev. 2004, 248, 135-146.

45. Metin, Ö.; Özkar, S. Water soluble nickel(0) and cobalt(0) nanoclusters stabilized by poly(4-styrenesulfonic acid-co-maleic acid): Highly active, durable and cost effective catalysts in hydrogen generation from the hydrolysis of ammonia borane. Int. J. Hydrogen Energy 2011, 36, 1424-1432.

46. Zahmakiran, M.; Özkar, S. Metal nanoparticles in liquid phase catalysis; from recent advances to future goals. Nanoscale 2011, 3, 3462-3481.

47. Can, H.; Metin, Ö. A facile synthesis of nearly monodisperse ruthenium nanoparticles and their catalysis in the hydrolytic dehydrogenation of ammonia borane for chemical hydrogen store. Appl. Cat. B Environ. 2012, 125, 304-310. 
48. Liang, H.; Chen, G.; Desinan, S.; Rosei, R.; Rosei, F.; Ma, D. In situ facile synthesis of ruthenium nanocluster catalyst supported on carbon black for hydrogen generation from the hydrolysis of ammonia-borane. Int. J. Hydrogen Energy 2012, 37, 17921-17927.

49. Basu, S.; Brockman, A.; Gagore, P.; Zheng, Y.; Ramachandran, P.V.; Delgass, W.N. Chemical kinetics of Ru-catalyzed ammonia borane hydrolysis. J. Power Sources 2009, 188, 238-243.

(C) 2015 by the authors; licensee MDPI, Basel, Switzerland. This article is an open access article distributed under the terms and conditions of the Creative Commons Attribution license (http://creativecommons.org/licenses/by/4.0/). 